\title{
Factor V Deficiency with a Thrombotic Clinical Phenotype
}

\author{
Meera Sridharan, MD, PhD ${ }^{1,2}$ Lea M. Coon, MS, LCGC
}

Dong Chen, MD, PhD²

Rajiv K. Pruthi, MBBS ${ }^{1,2}$
Address for correspondence Rajiv K. Pruthi, MBBS, Division of Hematology, Department of Internal Medicine, Mayo Clinic, 200 First Street, SW, Rochester, MN 55905 (e-mail: pruthi.rajiv@mayo.edu).
Coagulation factor V (FV) is a large $330-\mathrm{kD}$ glycoprotein mainly synthesized in the liver and megakaryocytes. Eighty percent of blood FV circulates in plasma while the remaining $20 \%$ is stored within platelet $\alpha$ granules. ${ }^{1}$ In its active form (FVa), it is an essential cofactor for factor Xa, assisting the conversion of prothrombin to thrombin. The procoagulant activity of FVa is regulated by activated protein C (APC), which cleaves multiple peptide bonds in FVa. Cleavage of FV by APC at residue p.Arg534 ("Arg506" in legacy nomenclature) converts FV into an anticoagulant protein (FVac) that lacks procoagulant activity and serves as a cofactor to APC, which in synergy with protein $\mathrm{S}$ mediates degradation of FVIIIa. ${ }^{1} \mathrm{FV}$ is also a carrier of, and cofactor to, the coagulation inhibitor tissue factor pathway inhibitor. ${ }^{2,3}$ Defects in FV may therefore result in either hemorrhagic or thrombotic phenotypes. The FV Leiden mutation (“Arg506Gln" in legacy nomenclature; p.Arg534Gln in NM_000130.4) is the most common defect in FV leading to a thrombotic phenotype, while severe FV deficiency, an autosomal recessive condition due to point mutations in the FV gene (F5), can be associated with mild or severe bleeding. ${ }^{4}$

Though defects in FV may cause either bleeding or thrombosis, it is rare for FV deficiency per se to predispose to thrombosis. Here, we present a case of an individual with recurrent episodes of thrombosis who was found to have FV deficiency. This 33-year-old white male, who had previously undergone hemostatically uneventful hypospadias repair and pilonidal cyst removal, experienced two episodes ( 3 and 1 years prior to current presentation) of superficial phlebitis of the right lower extremity which were managed conservatively (anti-inflammatory agents and compression stockings). He presented to our institution for management of bilateral segmental and right lobar pulmonary emboli (PE; documented on CT angiography) and soleal vein thrombosis. The thrombosis was felt to be provoked by ankle trauma that occurred 1 month prior to the thrombosis. Management consisted of initial enoxaparin, with transition to rivaroxaban for 3 months (after which CT angiography demonstrated resolution of PE), and then aspirin $81 \mathrm{mg}$ daily was initiated.

While on enoxaparin, thrombophilia testing demonstrated normal activities of antithrombin and protein $\mathrm{C}$, as well as normal free protein $S$ antigen. Activated protein $C$ resistance ratio (APC-R), a ratio calculated based on APTT obtained with and without added APC (both diluted in FV-deficient plasma), was indeterminate, but he did not have the factor $\mathrm{V}$ Leiden mutation. He also did not have the prothrombin "G20210A" thrombosis-susceptibility variant in F2, NM_000506.4: c. ${ }^{* 97 G}$ $>$ A. Follow-up testing off anticoagulation demonstrated a slightly prolonged prothrombin time (PT) of 13.7 seconds (s) (reference range: 10.3-12.8 seconds) and activated partial thromboplastin time (APTT) of 42 seconds (reference range: 26-36 seconds. APTT corrected with equal volume mixing study with normal plasma. Reflexive testing demonstrated factor V activity (FV:C) of 20\% (reference range: 70-165\%).

Approximately 2 years later, he underwent a left arthroscopic shoulder capsular shift and labral repair with no hemostatic support, and no bleeding complications were reported. Two weeks later, evaluation of left arm pain documented presence of thrombosis in the brachial and cephalic veins. He received 3 months of rivaroxaban; follow-up upper extremity ultrasound demonstrated resolution of thrombus.

Approximately 18 months later, he presented with left calf pain with swelling and shortness of breath. He was found to have an acute occlusive thrombus in the posterior tibial, peroneal, and soleal veins. He also had bilateral PE. Unlike the prior episodes of deep vein thrombosis (DVT) and PE, no provoking etiology could be identified. He was started on warfarin with plans for indefinite treatment.

Lupus anticoagulant was assessed at six different times during the patient's clinical course, both on and off anticoagulation. STACLOT-LA was indeterminate when patient was on warfarin but negative when tested off warfarin. published online January 10, 2019
Issue Theme Editorial Compilation VI; Guest Editors: Emmanuel J. Favaloro, PhD, FFSc (RCPA), and Giuseppe Lippi, MD.
Copyright $\odot 2019$ by Thieme Medical Publishers, Inc., 333 Seventh Avenue, New York, NY 10001, USA. Tel: +1(212) 584-4662.
DOI https://doi.org/ 10.1055/s-0038-1677041. ISSN 0094-6176. 
Platelet neutralization procedure (PNP) was repeatedly negative. Dilute Russel's viper venom time (DRVVT) was positive; DRVVT screen, 1:1 normal pooled plasma mix, and phospholipid confirmed ratios were all greater than 1.2 (reference range $<1.2$ ), on three occasions when the patient was off of anticoagulation and this was thought to be related to FV deficiency. Immunoglobulin M and immunoglobulin $G$ anticardiolipin and anti-beta 2 glycoprotein antibodies were negative.

Molecular genetic testing using a next-generation sequencing (NGS) panel to assess SERPINC, F2, F5, F7, F8, F9, F10, F11, F12, F13A1, F13B, FGA, FGB, FGG, PROC, PROCR, PROS, THBD, and $V W F$ was performed, revealing the presence of four variants (two in F5, one in PROCR [protein C receptor gene], and one in the FGG [fibrinogen gamma chain gene]; - Table 1).

Family history was notable for his mother having a DVT and PE thought to be related to oral contraception. She had $\mathrm{FV}: \mathrm{C}$ of $46 \%$ and did not have the factor V Leiden "R506Q" mutation or prothrombin "G20210A" mutation. She was not available for further genetic testing.

Venous thromboembolism (VTE) is a major cause of morbidity and mortality worldwide and some individuals are found to have an underlying genetic predisposition to developing VTE. FV Leiden, the most common inherited thrombophilia in the white population, is due to a mutation in exon 10 of $F V$ (c.1601G > A, p.Arg534Gln) that gives rise to a molecule that is resistant to inactivation by APC. ${ }^{5}$ Two additional FV allelic variants that could possibly contribute to APC resistance have also been reported: c.1001G

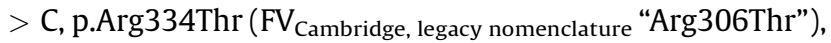

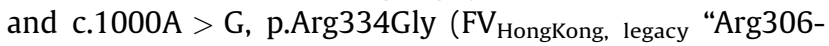
Gly"). Both mutations affect the same cleavage site responsible for complete loss of FVa procoagulant activity. ${ }^{6}$

The molecular basis of previously reported cases of heterozygous FV Leiden carriers experiencing thrombosis in the setting of FV deficiency was felt to be due to pseudo-homozygosity of FV Leiden mutation ( $\mathbf{- T a b l e ~} \mathbf{2}$ ). For example, one case described a 41-year-old male with recurrent VTE who was found to be a heterozygote for FV Leiden and had a FV:C of $50 \%$. Of his two children, one was heterozygous for FV Leiden and one was heterozygous for FV deficiency, suggesting that the FV-deficiency trait segregated independently from FV Leiden mutation. No further molecular studies of $F 5$ were available for the proband or his children. ${ }^{7}$ Another study described a novel F5 gene mutation (c.4906G > A, p.Glu1636Lys) in three unrelated thrombotic patients with FV deficiency and either heterozygous for FV Leiden $(n=2)$ or the FV HR2 haplotype $(n=1)$. The causative role of c.4906G $>$ A in FV deficiency was verified by in vitro expression and characterization of the recombinant molecule. ${ }^{5}$ Another study investigated thrombosis risk of genetically characterized FV Leiden pseudohomozygotes with FV Leiden heterozygotes and homozygotes and FV Leiden pseudohomozygotes showed a pattern similar to homozygotes. ${ }^{8}$ The patient described in the current case had low $\mathrm{FV}: \mathrm{C}$ with a thrombotic clinical phenotype without the presence for FV Leiden mutation.

The gene for human $\mathrm{FV}(F 5)$ is localized to chromosome 1q24.2 and contains 25 exons and 24 introns. In our patient,

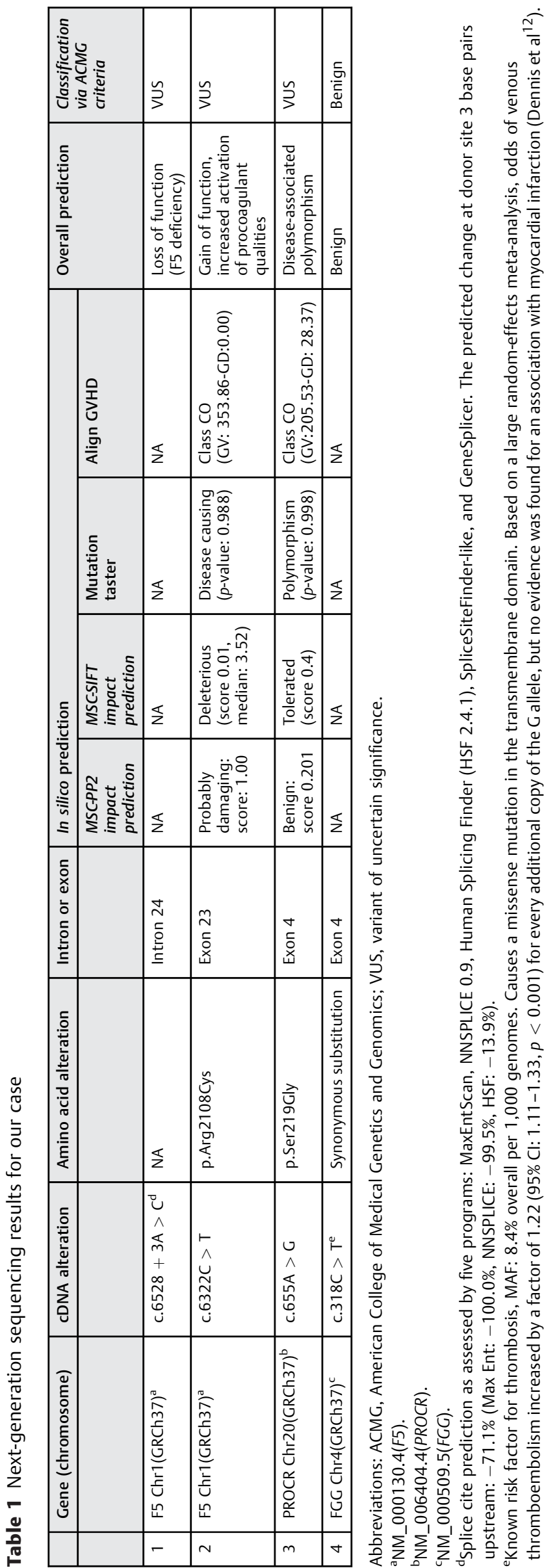


Table 2 FV deficiency and clinical thrombosis as reported in the literature

\begin{tabular}{|c|c|c|c|c|c|}
\hline $\begin{array}{l}\text { Publication } \\
(n=\text { number of } \\
\text { individuals reported })^{a}\end{array}$ & $\begin{array}{l}\text { Age } \\
\text { (gender) }\end{array}$ & Genetic variants in $\mathrm{F}^{\mathrm{b}}$ & Clinical manifestations & FV activity & $\begin{array}{l}\text { Family } \\
\text { study }\end{array}$ \\
\hline $\begin{array}{l}\text { Zehnder and Jain, } 1996 \\
(n=1)\end{array}$ & $41(\mathrm{M})$ & $\begin{array}{l}\text { - Heterozygous for FV Leiden } \\
\text { - No other genetic } \\
\text { analysis performed }\end{array}$ & Recurrent VTE & $50 \%$ & Yes \\
\hline $\begin{array}{l}\text { Lunghi et al, } 2005 \\
(n=3)\end{array}$ & $\begin{array}{l}\mathrm{M}, n=2 \\
\mathrm{~F}, n=1\end{array}$ & $\begin{array}{l}\text { - Heterozygous E1608 K } \\
\text { (HGVS: p.E1636K }(n=3) \\
\text { - Heterozygous for } \\
\text { FV Leiden }(n=2) \\
\text { - FVHR2 haplotype }(n=1)\end{array}$ & DVT & $\begin{array}{l}55 \%, 20 \%, \\
\text { NA }\end{array}$ & Yes \\
\hline $\begin{array}{l}\text { Simioni et al, } 2005 \\
(n=5)\end{array}$ & NA & $\begin{array}{l}\text { - Heterozygous for } \\
\text { FV Leiden ( } n=5) \\
\text {-Q1894X (HGVS: p.Q1922X) } \\
\circ \text { G2049X (HGVS: p.G2077X) } \\
\text { ○ G2112D (HGVS: p.G2140D) } \\
\text { - P1224X (HGVS: p.P1252X) } \\
\circ \text { Y1702 (HGVS: p.Y1730C) }\end{array}$ & VTE & $45-61 \%$ & Yes \\
\hline $\begin{array}{l}\text { Nishiya et al, } 2009 \\
(n=1)\end{array}$ & $13(\mathrm{M})$ & $\begin{array}{l}\text { - Homozygous mutation } \\
\text { W1920R (HGVS: p. W1948R) }\end{array}$ & DVT & $10 \%$ & Yes \\
\hline $\begin{array}{l}\text { Janicki et al, } 2013 \\
(n=1)\end{array}$ & $26(F)$ & $\begin{array}{l}\text { - Homozygous R2102H } \\
\text { (HGVS: p.Arg2130His), } \\
\text { associated with FV deficiency } \\
\text { - Homozygous R513K } \\
\text { (HGVS: p. R541K), } \\
\text { associated with thrombosis } \\
\text { - Homozygous D107H } \\
\text { (HGVS: p.D135H), } \\
\text { associated with miscarriages }\end{array}$ & $\begin{array}{l}\text { Bleeding episodes } \\
\text { and miscarriages }\end{array}$ & $\begin{array}{l}\text { Severe } \\
\text { deficiency }\end{array}$ & Yes \\
\hline $\begin{array}{l}\text { Manotti et al, } 1989 \\
(n=1)\end{array}$ & $62(\mathrm{M})$ & No genetic testing & DVT and PE & $12 \%$ & Yes \\
\hline $\begin{array}{l}\text { Reich et al, } 1976 \\
(n=1)\end{array}$ & $36(F)$ & No genetic testing & $\begin{array}{l}\text { Thrombophlebitis } \\
\text { and PE }\end{array}$ & $14 \%$ & Yes \\
\hline $\begin{array}{l}\text { Miller, } 1960 \\
(n=1)\end{array}$ & $32(F)$ & No genetic testing & $\begin{array}{l}\text { Primarily bleeding but } \\
\text { one episode of clotting }\end{array}$ & $<2 \%$ & Yes \\
\hline $\begin{array}{l}\text { García-Noblejas et al, } \\
2005(n=1)\end{array}$ & $36(\mathrm{M})$ & No genetic testing & $\begin{array}{l}\text { PE after receiving FFP } \\
\text { for FV deficiency } \\
\text { and hemarthrosis }\end{array}$ & $1 \%$ & No \\
\hline
\end{tabular}

Abbreviations: DVT, deep vein thrombosis; F, female; FFP, fresh frozen plasma; FV, factor V; M, male; NA, not available; PE, pulmonary embolism; VTE, venous thromboembolism.

an studies including more than one family member, only the proband was reported.

${ }^{\mathrm{b}}$ All variants are reported using Human Genome Variation Society nomenclature based on F5 transcript NM_000130.4, GRCh37; if the original article reported legacy nomenclature, then that is also provided.

NGS allowed the identification of two heterozygous variants in 55 , one in intron 24 and one in exon 23 , which may be contributing to FV deficiency and thrombotic clinical phenotype, respectively. In-silico splicing predictors (MaxEntScan, NNSPLICE 0.9, Human Splicing Finder [HSF 2.4.1], SpliceSiteFinder-like, GeneSplicer) available through variant visualization software Alamut Visual were used to predict the variant's impact on splicing. Though further in vitro analysis is required, our in silico analysis suggested that the intron variant c.6528 $+3 \mathrm{~A}>\mathrm{C}$ could lead to FV deficiency. This variant is predicted to abolish or weaken splicing at the downstream canonical splice, which would lead to retention of intron 24 (-Table 1 ). A premature stop codon would occur at c.6528 + 34_6528 + 3, leaving the transcript to be subject to nonsense mediated decay. Other studies have demonstrated that intron retention is associated with lower protein level, and those transcripts that escape nonsense-mediated decay are not actively translated. ${ }^{9}$ Of note, the c.6528 + 3A > C alteration is known to the large population database gnomAD, ${ }^{10}$ where it was found in the heterozygous state in $2 / 55,723$ Europeans and in no other population $\left(0 / 67,185\right.$ individuals screened).$^{10}$

The other alteration detected in our case, c.6322C > T, p.Arg2108Cys, is a missense variant leading to substitution of arginine with cysteine in the FV C2 domain, which is essential for binding the light chain to the phosphatidyl serine-rich membranes of activated platelets. The $\mathrm{C} 2$ domain of $\mathrm{FV}$ contains three adjacent loops or "spikes" (Ser21-Trp31, Asn39-Asn45, 
and Gly75-Tyr84) that are primary membrane binding sites. Spikes 1 and 3 are capped by hydrophobic residues that may immerse themselves in the polar membrane core. Arginine 2108 , a basic amino acid, is at the apex of "spike" 2 and makes contact with the negatively charged phosphate groups of the membrane. ${ }^{11}$ The substitution of cysteine (which is hydrophobic) for arginine (which is basic) would create another site of membrane immersion that might strengthen the binding between the membrane and FV, or help it bind to more platelet membranes that have a lower phosphatidyl-L serine concentration. As noted earlier, in vitro analysis would need to be performed to prove these hypotheses. Additionally, our analysis could not determine whether c.6322C $>\mathrm{T}$ is in cis or trans to $\mathrm{c} .6528+3 \mathrm{~A}>\mathrm{C}$. In gnomAD, F5 C.6322C > T was found only in the heterozygous state in 1/7,651 Africans, $1 / 8,620$ East Asians, 1/15,389 South Asians, and 1/55,650 Europeans, and in no other population group $(0 / 35,593) .{ }^{10}$ No phenotypic data of these individuals are publically available, and per American College of Medical Genetics and Genomics (ACMG) guidelines further evidence is needed to reclassify these variants of uncertain significance and pathogenic or benign variation.

In addition to the F5 variants, our patient also had heterozygous variants in FGG and PROCR. The variant in FGG causes a synonymous amino acid substitution with no predicted impact on splicing and is benign per ACMG guidelines. The PROCR variant is likely a disease-associated polymorphism, and other studies have demonstrated that it is a known risk factor for thrombosis. ${ }^{12,13}$

Additional cases of clinical thrombosis and FV deficiency in patients without the FV Leiden mutation have been described; however, many do not detail patient follow-up. For example, direct sequencing of the F5 gene in a 13-yearold boy with DVT and FV deficiency demonstrated a novel homozygous mutation: c.5842T > C, p.Trp1948Arg. Sequencing of this patient's parents demonstrated that they were heterozygous for this mutation. ${ }^{14}$ Another study performed F5 NGS in a patient with severe FV deficiency, as well as in her asymptomatic parents and newborn baby. The proband was homozygous for three separate missense mutations in the coding sequence of F5. Only one of the three detected missense mutations was described previously in the setting of FV deficiency (c.6305G > A, p.Arg2102His) and it was suggested that this variant was causative for FV deficiency. The other two variants were associated with thrombosis or increased risk of preterm delivery. ${ }^{15}$ Our review of the literature also identified additional family studies describing cases of FV deficiency and clinical thrombosis; however, these do not present genetic testing data. ${ }^{16-19}$

Given the rarity of its presentation, there are no guidelines for management of clinical thrombosis in patients with FV deficiency. Antithrombotic treatment is based on clinical expertise and adaptation of guidelines for nonbleeding patients as well as guidelines that are currently applied for classical hemophilia patients. ${ }^{20}$ Making management more challenging in these patients is the fact that clinical symptoms do not correlate with FV:C as some individuals with FV: $\mathrm{C}<1 \%$ do not have severe bleeding manifestations. It has been hypothesized that residual platelet $\mathrm{FV}: \mathrm{C}$ is a determi- nant of the severity of clinical bleeding a patient with FV deficiency will experience. ${ }^{21}$ Due to the variable clinical phenotype that occurs in patients with FV deficiency, specific management of clinical thrombosis needs to be individualized. Our patient had no hemorrhagic episodes; therefore, he was treated with standard doses of anticoagulation. He tolerated anticoagulation with no complications and continues on warfarin. He has not had a recurrent thrombosis while on anticoagulation.

In conclusion, this case highlights the clinical variability that can be seen in individuals with defects in the F5 gene. Though FV Leiden is the most common inherited disorder of thrombophilia, other variants in F5 have been implicated in clinical thrombosis. Management of a person with FV deficiency should be based on clinical symptoms and not on FV: C levels due to the variability in clinical presentation.

Conflicts of Interest None.

\section{References}

1 Duga S, Asselta R, Tenchini ML. Coagulation factor V. Int J Biochem Cell Biol 2004;36(08):1393-1399

2 Dahlbäck B. Novel insights into the regulation of coagulation by factor $\mathrm{V}$ isoforms, tissue factor pathway inhibitor $\alpha$, and protein $\mathrm{S}$. J Thromb Haemost 2017;15(07):1241-1250

3 Dahlbäck B. Pro- and anticoagulant properties of factor $V$ in pathogenesis of thrombosis and bleeding disorders. Int J Lab Hematol 2016;38(Suppl 1):4-11

4 Duckers C, Simioni P, Rosing J, Castoldi E. Advances in understanding the bleeding diathesis in factor V deficiency. Br J Haematol 2009;146 (01):17-26

5 Lunghi B, Scanavini D, Castoldi E, et al. The factor V Glu1608Lys mutation is recurrent in familial thrombophilia. J Thromb Haemost 2005;3(09):2032-2038

6 Norstrøm E, Thorelli E, Dahlbäck B. Functional characterization of recombinant FV Hong Kong and FV Cambridge. Blood 2002;100 (02):524-530

7 Zehnder JL, Jain M. Recurrent thrombosis due to compound heterozygosity for factor $\mathrm{V}$ Leiden and factor $\mathrm{V}$ deficiency. Blood Coagul Fibrinolysis 1996;7(03):361-362

8 Simioni P, Castoldi E, Lunghi B, Tormene D, Rosing J, Bernardi F. An underestimated combination of opposites resulting in enhanced thrombotic tendency. Blood 2005;106(07):2363-2365

9 Middleton R, Gao D, Thomas A, et al. IRFinder: assessing the impact of intron retention on mammalian gene expression. Genome Biol 2017;18(01):51

10 Lek M, Karczewski KJ, Minikel EV, et al; Exome Aggregation Consortium. Analysis of protein-coding genetic variation in 60,706 humans. Nature 2016;536(7616):285-291

11 Macedo-Ribeiro S, Bode W, Huber R, et al. Crystal structures of the membrane-binding $\mathrm{C} 2$ domain of human coagulation factor $\mathrm{V}$. Nature 1999;402(6760):434-439

12 Dennis J, Johnson CY, Adediran AS, et al. The endothelial protein C receptor (PROCR) Ser219Gly variant and risk of common thrombotic disorders: a HuGE review and meta-analysis of evidence from observational studies. Blood 2012;119(10):2392-2400

13 Medina P, Navarro S, Estellés A, Vayá A, Bertina RM, España F. Influence of the $4600 \mathrm{~A} / \mathrm{G}$ and $4678 \mathrm{G} / \mathrm{C}$ polymorphisms in the endothelial protein $C$ receptor (EPCR) gene on the risk of venous thromboembolism in carriers of factor V Leiden. Thromb Haemost 2005;94(02):389-394 
14 Nishiya K, Kikukawa Y, Shinozawa K, Yada H, Fukutake K, Shima M. Deep venous thromboembolism in a patient of factor $V$ deficiency. Paper presented at the 22nd Congress of the International Society of Thrombosis and Haemostasis. Boston, MA2009

15 Janicki PK, Vaida S, Al-Mondhiry HA. Targeted next-generation resequencing of f5 gene identifies novel multiple variants pattern in severe hereditary factor v deficiency. Case Rep Genet 2013;2013:941684

16 Reich NE, Hoffman GC, deWolfe VG, Van Ordstrand HS. Recurrent thrombophlebitis and pulmonary emboli in congenital factor 5 deficiency. Chest 1976;69(01):113-114

17 Manotti C, Quintavalla R, Pini M, Jeran M, Paolicelli M, Dettori AG. Thromboembolic manifestations and congenital factor $\mathrm{V}$ deficiency: a family study. Haemostasis 1989;19(06):331-334
18 Miller SP. Coagulation dynamics in factor V deficiency: a family study, with a note on the occurrence of thrombophlebitis. Thromb Diath Haemorrh 1965;13:500-515

19 García-Noblejas A, Osorio S, Durán AI, et al. Pulmonary embolism in a patient with severe congenital deficiency for factor $\mathrm{V}$ during treatment with fresh frozen plasma. Haemophilia 2005;11(03): 276-279

20 Ruiz-Saez A. Occurrence of thrombosis in rare bleeding disorders. Semin Thromb Hemost 2013;39(06):684-692

21 Duckers C, Simioni P, Spiezia L, et al. Residual platelet factor V ensures thrombin generation in patients with severe congenital factor V deficiency and mild bleeding symptoms. Blood 2010;115 (04):879-886 